\title{
Please Reduce Cycle Time
}

Brian Schultz

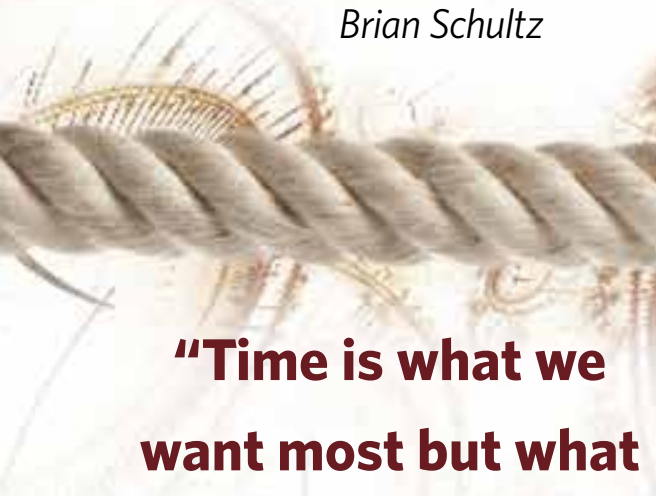

we use worst."

-William Penn

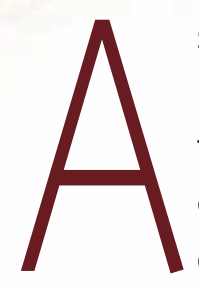

s William Penn noted centuries ago, time might be our most precious resource but it is also one that we have trouble managing effectively. While cost-performance trade-offs get a lot of emphasis in developmental acquisition efforts, schedule or cycle time is also an important part of the cost-schedule-performance triad that determines outcomes. Note that the terms "cycle time" and "schedule" will be used interchangeably in this article to mean the total time required from program initiation until Initial Operational Capability (IOC).

Acquisition cycle time continues to be a "hot topic." Over years, many have argued that it simply takes too long to get capability to the warfighter and that fundamental reform is needed to address this issue. More recently, we see the imperative to deploy capabilities faster in light of cyber and asymmetric threats. Several studies have validated this notion that it is taking longer now than in past decades to develop and field Department of Defense $(\mathrm{DoD})$ weapon systems. Despite all the attention and reforms, the issue has not gone away. In fact, it may even be more problematic now than in the past because of program complexity, use of new and advanced materials, software-intensive designs, advanced manufacturing techniques and many other factors. 


\section{Report Documentation Page}

Form Approved

OMB No. 0704-0188

Public reporting burden for the collection of information is estimated to average 1 hour per response, including the time for reviewing instructions, searching existing data sources, gathering and maintaining the data needed, and completing and reviewing the collection of information. Send comments regarding this burden estimate or any other aspect of this collection of information,

including suggestions for reducing this burden, to Washington Headquarters Services, Directorate for Information Operations and Reports, 1215 Jefferson Davis Highway, Suite 1204, Arlington

VA 22202-4302. Respondents should be aware that notwithstanding any other provision of law, no person shall be subject to a penalty for failing to comply with a collection of information if it

does not display a currently valid OMB control number.

\begin{tabular}{|c|c|}
\hline $\begin{array}{l}\text { 1. REPORT DATE } \\
\text { DEC } \mathbf{2 0 1 4}\end{array}$ & $\begin{array}{l}\text { 3. DATES COVERED } \\
\mathbf{0 0 - 0 0 - 2 0 1 4} \text { to 00-00-2014 }\end{array}$ \\
\hline \multirow{3}{*}{$\begin{array}{l}\text { 4. TITLE AND SUbTITLE } \\
\text { Please Reduce Cycle Time }\end{array}$} & 5a. CONTRACT NUMBER \\
\hline & 5b. GRANT NUMBER \\
\hline & 5c. PROGRAM ELEMENT NUMBER \\
\hline \multirow[t]{3}{*}{ 6. AUTHOR(S) } & 5d. PROJECT NUMBER \\
\hline & 5e. TASK NUMBER \\
\hline & 5f. WORK UNIT NUMBER \\
\hline $\begin{array}{l}\text { 7. PERFORMING ORGANIZATION NAME(S) AND ADDRESS(ES) } \\
\text { Defense Acquisition University,9820 Belvoir Road,Fort } \\
\text { Belvoir,VA,22060-5565 }\end{array}$ & $\begin{array}{l}\text { 8. PERFORMING ORGANIZATION } \\
\text { REPORT NUMBER }\end{array}$ \\
\hline \multirow[t]{2}{*}{ 9. SPONSORING/MONITORING AGENCY NAME(S) AND ADDRESS(ES) } & 10. SPONSOR/MONITOR'S ACRONYM(S) \\
\hline & $\begin{array}{l}\text { 11. SPONSOR/MONITOR'S REPORT } \\
\text { NUMBER(S) }\end{array}$ \\
\hline
\end{tabular}

12. DISTRIBUTION/AVAILABILITY STATEMENT

Approved for public release; distribution unlimited

13. SUPPLEMENTARY NOTES

14. ABSTRACT

15. SUBJECT TERMS

16. SECURITY CLASSIFICATION OF:

\begin{tabular}{c|c|c|c|}
$\begin{array}{c}\text { a. REPORT } \\
\text { unclassified }\end{array}$ & $\begin{array}{c}\text { b. ABSTRACT } \\
\text { unclassified }\end{array}$ & $\begin{array}{c}\text { c. THIS PAGE } \\
\text { unclassified }\end{array}$ & $\begin{array}{c}\text { Same as } \\
\text { Report (SAR) }\end{array}$
\end{tabular}

\begin{tabular}{c|l}
$\begin{array}{c}\text { 18. NUMBER } \\
\text { OF PAGES }\end{array}$ & 19a. NAME OF \\
$\mathbf{4}$ & RESPONSIBLE PERSON \\
& \\
\end{tabular}

Standard Form 298 (Rev. 8-98) Prescribed by ANSI Std Z39-18 
A DoD Inspector General audit report (No. D-2002-032, Dec. 28, 2001) identified that in 1960 major defense acquisition programs (MDAPs) required seven years for completion, again defined as program start to IOC. In 1996, this metric had grown to 11 years. A more recent Government Accountability Office study (GAO-14-145T) highlighted that the average delay in achieving IOC on MDAPs had grown from 22 months in 2008 to 27 months in 2012 while cost growth increased from $\$ 323$ billion to $\$ 411$ billion. Although the purpose of this discussion is not to examine the history or causes of acquisition cycle time growth, it is important to understand why there is such an emphasis on schedule and getting capability to the warfighter more rapidly.

Cycle time can be addressed in the context of "micro" and "macro" perspectives. Micro-cycle time is defined here as the specific program schedule tasks and dependencies necessary to get a capability fielded, based on the program's unique technical and programmatic aspects. Thus, it is addressed in the context of a specific program and is the responsibility of the program manager (PM) to plan and execute-including any programmatic assumptions, constraints and logic. reasonable risks. The "will" and "shall" statements in the regulatory guidance do not necessarily override the mandate for a tailored approach. So, even if one is not using an accelerated model, opportunities to accelerate the program schedule should be explored.

Both macro- and micro-cycle time aspects should be addressed as part of the overall risk- and opportunity-management framework. The following discussion provides some examples of cycle-time risks and opportunities based on my experiences. A robust and continuous approach to assessing and managing schedule risks and opportunities can be very useful in getting to a successful acquisition outcome and help answer the question, "What can we do to reduce cycle time?"

\section{Risks}

Schedule logic and assumptions: PMs typically build a Government Roadmap Schedule and an Integrated Master Plan (IMP) that outline the overall schedule for the program and key events and criteria to complete the events. The IMP and Government Roadmap Schedule provided to the contractor may include hard dates that contractors must meet. These program

\section{Implementing concurrent efforts and/or eliminating some tasks are often used to enable this rapid approach, recognizing that risk and program inefficiencies may increase.}

On the other hand, macro-cycle time is defined as the impact that the overall acquisition management and decision-supportsystem structures have on the time it takes to field a capability from Milestone B to IOC. For example, macro-cycle time considerations would include time necessary for the processes and approvals within the DoD decision-support systems.

Macro-cycle time considerations are addressed in statutory, regulatory and policy documents such as the new interim DoDI 5000.02. Note that the new 5000.02 Instruction includes an Accelerated Acquisition Program model, where schedule considerations override other programmatic constraints. Implementing concurrent efforts and/or eliminating some tasks are often used to enable this rapid approach, recognizing that risk and program inefficiencies may increase.

Another aspect of macro-cycle time considerations in the 5000.02 is tailoring each program based on the unique aspects associated with it. The Accelerated Acquisition Program model is called out as one specific example of tailoring, and many others are possible. The basic premise suggests that PMs should look for opportunities to structure their programs in a manner that reduces time and cost, while accepting constraints are then used as the basis for the contractor-developed Integrated Master Schedule (IMS) that establishes dates and schedule-task relationships for the program execution.

In a competitive environment, companies may be reluctant to identify an overly aggressive schedule as high risk since this could jeopardize their competitive positions. PMs should encourage open dialogue with industry in the pre-award planning stage to assess the amount of time needed to complete the planned work and to validate schedule assumptions before contract award. If we decide to take on a high-risk schedule, at least we can manage it as such and ensure actions are planned to address contingencies if the risks are realized.

The logic associated with the schedule relationships should also be carefully reviewed and periodically revisited. This logic can be flawed and change over time as we learn more and better understand the schedule interrelationships. It may also be wise to keep the complexity at a manageable level.

I learned this lesson while managing a software-intensive program. We decided to create a very detailed master schedule with multiple supporting subschedules that linked and 
automatically updated the master schedule if all the inputs were entered correctly. The effort was well intentioned as the program involved a large team of developers and engineers working concurrently on several modules. However, the schedule and subschedules became so complicated and difficult to manage that they became unusable. We ended up reverting to a simpler schedule that provided enough oversight to keep on top of key tasks and actual progress. We also adjusted the schedule several times based on the knowledge of developer velocity and features that could be descoped and/or deferred.

Use of Commercial Off-the-Shelf (COTS) products: Using COTS offers many benefits and is prescribed in DoD Directive 5000.01 as the preferred approach to satisfying user needs. COTS can also present risks to a program and has been at the heart of significant cost and schedule delays within DoD. The issue has not been the COTS product itself but rather attempts to modify it and/or not fully understanding the COTS product.

A Dec. 23, 2013, Reuters article, "Why the Pentagon's accounting fixes end up broken," highlighted a common thread of several failed Enterprise Resource Planning (ERP) projects. A COTS product is chosen for an ERP solution but is then modified to reflect the legacy-system business model. These COTS modifications create a unique software product that is no longer COTS and becomes difficult to maintain. Furthermore, the benefits of COTS-such as the ability to leverage upgrades, training and support-can be lost.

Years ago, I observed an ERP system implementation that encountered this exact model. The modified COTS software worked and passed the acceptance tests but never was implemented by the customer due to the issues associated with maintaining it. Other programs apparently have learned this same lesson and the word is out that, if you decide to use COTS, you need to adopt the business process model it is based on rather than try to keep your existing processes in place as part of the COTS implementation.

For hardware, COTS can also present some risks. Many programs use COTS computers and servers, even as part of their mission-computing design. Since these items can quickly become obsolete and no longer supported by the original manufacturer, PMs should plan appropriate mitigations, including the use of periodic technology updates.

Inadequate planning: The imperative to accelerate can backfire and actually be counterproductive if not planned and managed properly. A good example is the use of Undefinitized Contract Actions (UCAs) to accelerate the start of development. On the surface, one might expect a faster overall schedule since it avoids the often lengthy upfront process of proposal development and negotiations before work starts. However, according to the Under Secretary of Defense for Acquisition, Technology, and Logistics' 2013 Annual Report on the Performance of the Defense Acquisition System, UCAs are identified as contributors to cost and schedule growth in DoD development contracts. UCAs were not correlated with cost and schedule growth in early production.

Another example is rushing the contracting cycle to stay on schedule. This often starts with the release to industry of the request for proposal (RFP). Given the lead time involved in contracting cycles, the temptation can arise to accelerate the RFP development and release, bypassing internal reviews and/ or skipping a draft RFP release for industry comment. Some might refer to this behavior as schedule driven versus event driven, as detailed in Dr. Mark Husband's March-April 2014 Defense AT\&L article, "Schedule or Event Driven?"

Every time I have tried to accelerate an RFP release, it ended up costing more time to correct issues such as inconsistencies or lack of clarity in RFP requirements. Industry will provide valuable feedback in a draft RFP that will often help the government team develop a better final RFP that can avoid future perturbations. While I don't have any data to back it up, my experience suggests that a very robust acquisition strategy and RFP planning effort saves time in the overall schedule and helps DoD get better outcomes.

\section{Opportunities}

Concurrency: I had a great experience working an aircraft mission-system upgrade program that employed a concurrent development and production strategy to accelerate the cycle time for fielding. While this strategy was risky, the risks were identified and managed jointly by the contractor and government team in a robust and transparent manner. When the program was planned, we expected that the software design would require several builds and iterations after a series of both ground and flight test events.

Meanwhile, the hardware designs were expected to be stable since we were integrating proven avionics, sensors and communication subsystems. A concurrent strategy was adopted, but only after careful analysis of the program plan, schedule and technical risks.

The teamwork and commitment of the joint DoD-contractor team played a big role in the success. Despite some bumps along the way, we delivered the capability within budget and on schedule. Note that due to the risks of this approach, a concurrent strategy is likely to get significant scrutiny and should be used only where all the right conditions are in place. These conditions include the right expertise, adequate resources (both human and financial), risks that are assessed as no higher than moderate, and buy-in from the entire team, including top management of the DoD and contractor teams.

Schedule is an important message: It may seem an oversimplification but sending a message to appropriate stakeholders, including the contractor, that schedule is important should not be overlooked. While cost-performance trades continue to get a lot of emphasis, how about addressing 
schedule-performance and cost-schedule trades similar to the Agile methodology in developing software? Note that one of the tenets of Agile software development methodology is that features will be managed as a variable in a given build but schedule and cost will remain fixed. This tenet is based on the idea that missing a delivery date will create greater overall dissatisfaction and impact than deferring some functionality until a later build. have learned and what we can improve. Cycle-time reduction will be difficult to achieve without an organizational culture of identifying and managing those opportunities.

Challenging the status quo and creating an environment where performance is rewarded can enable schedule compression opportunities. A few years ago, I worked on an urgent program to get a radar system installed in Iraq. When we looked at the

\section{Challenging the status quo and creating}

an environment where performance is rewarded can enable schedule compression opportunities.

Another practice involves setting clear expectations at the beginning of a new contract. Assuming a fixed-price type contract, it should be clear that missing a contract deliverable date is a serious breach. What some may not realize is that if the government allows schedule slips without consequences, the message is clear-that schedule is not important.

I once was told by a senior contracting official that accepting several late deliveries and then deciding to take action after the fact is too little, too late. It is the equivalent of saying that schedule is not important. Rather, the message should be clear that, if the contractor expects to miss any contractual delivery date, notice is to be given before the slip occurs accompanied with an explanation and get-well plan. This enables the two parties to discuss and attempt to resolve the issue before the slip and lets the contractor know that we expect performance in accordance with the contract. Appropriate corrective actions and contractual remedies also can be considered. Finally, the contractor's performance will be documented in the Contractors' Performance Assessment Report, which can be an important factor in future source selections.

Program teams have several tools to help manage the schedule and assess opportunities to accelerate. Some companies are using the theory of constraints (originated by Eli Goldratt, author of the book The Goal) as a basis for lean project management and lean manufacturing techniques to drive accelerated schedules and cost reductions. PMs need to understand what methodology their industry counterparts are using and why they believe it's appropriate.

Challenge the status quo: There is an old adage that goes something like "the schedule will expand to fit what we planned (even if we learn we can do it faster)." This humorous saying highlights an important opportunity when assessing a program schedule and looking for ways to get it done faster. The opportunity is to take a look at what we are doing, what we normal production lead time to get the radar produced and fielded, it was impossible to meet the need date. The project manager suggested that we tell the user we could not meet its requirement.

We then brainstormed and asked if the radar was currently in production and if we could divert another user's delivery with payback from the system we ordered. Sure enough, one of the users was happy to divert its planned delivery, enabling us to meet the compressed timeline. We also had to accelerate and combine some site-activation efforts and enlist support from other agencies to help us obtain access and eventual safety and accuracy certifications.

On another program, I observed an industry PM question why we needed so much documentation as part of a draft RFP. The documentation in question related to COTS items where a lengthy review of specifications added no value. This simple suggestion saved a lot of time and effort on work that the previous teams always did.

Conclusion: Cycle time is one of the key pillars of acquisition and has direct links and impacts to other programmatic elements. PMs must navigate through both macro and micro aspects of cycle-time risk and opportunities. The imperative to field systems and solutions quicker is challenging and will probably become more so, given the threat environment and pace of new technology. PMs should create an environment and expectation that cycle time is important in all aspects of acquisition processes and tasks, while ensuring credible execution to the baseline schedule!

All this cycle-time talk reminds me of the user who said to me: "We needed this capability yesterday. Why does it take so long?"

The author can be contacted at brian.schultz@dau.mil. 